\title{
Francisco Julio Lafargue y Carlos Buston: el episodio de "la mano femenina"
}

\author{
Enrique Laval
}

Programa de Estudios Médicos Humanísticos Facultad de Medicina Pontificia Universidad Católica de Chile

Recibido: 2 de noviembre de 2012

Correspondencia a: Enrique Laval revinf@sochinf.cl

\author{
Francisco Julio Lafargue and Carlos Buston: \\ the episode of "The feminine hand"
}

In this communication the personality and biographical data of Dr. Francisco Julio Lafargue, second Professor of Anatomy and Physiology of the School of Medicine of the University of Chile, as well as Dr. Carlos Buston, a military surgeon are described, transcribing the episode, regarded as "literary anecdote", involving both doctors in 1843 .

Key words: Francisco J. Lafargue, Carlos Buston, baffling episode.

Palabras clave: Francisco J. Lafargue, Carlos Buston, episodio desconcertante.

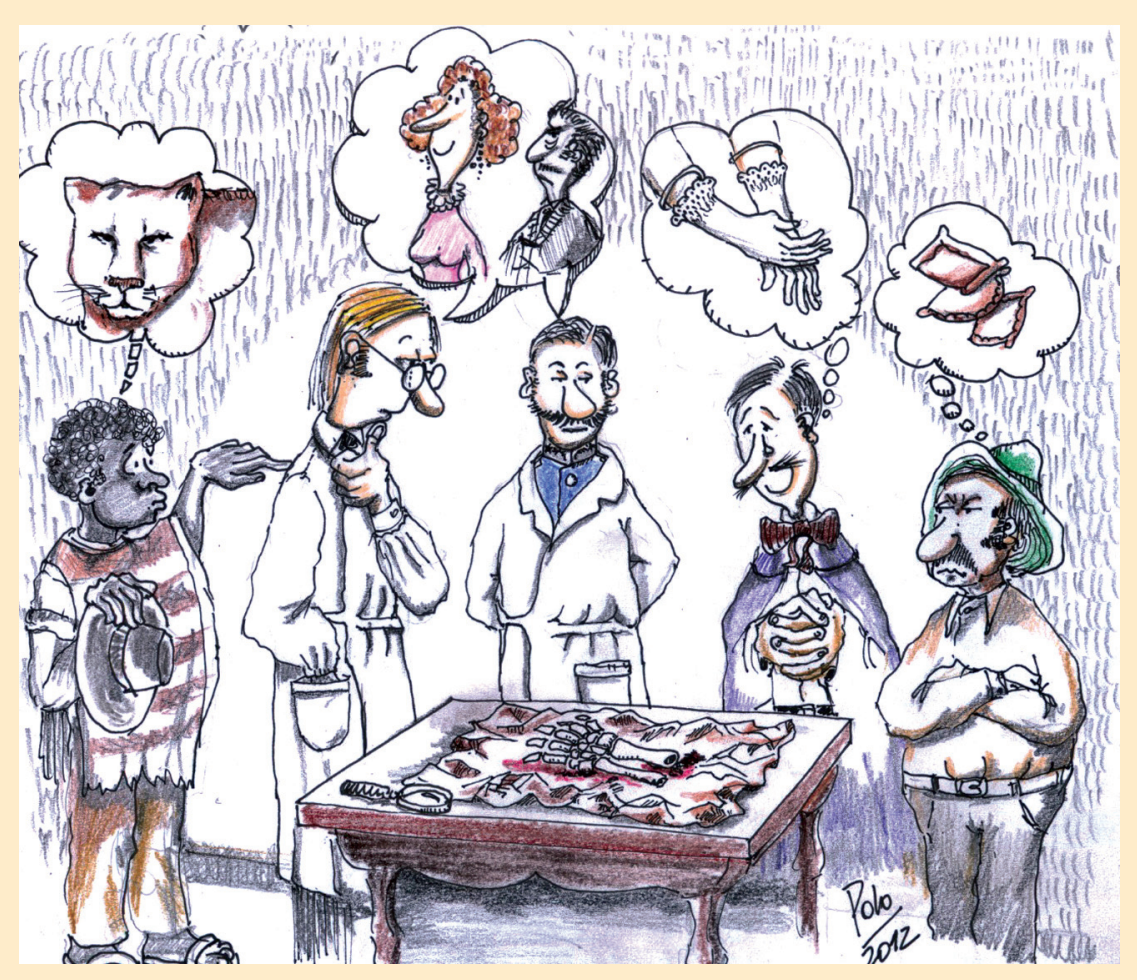

Nombramiento del doctor Francisco Julio Lafargue como profesor de anatomía y fisiología

$\mathrm{E}$ 1 día 19 de diciembre de 1840 fallecía el doctor Pedro Morán, primer profesor de anatomía fisiología de la naciente Escuela de Medicina de la era republicana, inserta en el Instituto Nacional ${ }^{1}$.

La clase vacante, en conformidad con el reglamento de 1832, se dio a oposición, presentándose al concurso los doctores Francisco Julio Lafargue, francés, llegado a Chile a fines de 1840 y Mariano Polar, peruano.

Con fecha 12 de abril de 1841, el Gobierno nombró como examinadores al rector del Instituto Nacional, Francisco Puente, al Presidente del Protomedicato, Agustín Nataniel Cox y a los profesores Guillermo Blest y Lorenzo Sazié.

Se acordó que el día 26 de dicho mes sería "el pique de puntos" y la "oposición el 28", pero no llegó ninguno de los examinadores a la cita. El rector del Instituto manifestó que no era la primera vez que los profesores de medicina faltaban sin dar aviso a una citación de exámenes; pero sin duda alguna, la razón de ello se debía a las numerosas exigencias de su trabajo profesional.

Tal vez por amonestación superior, los profesores se reunieron el día 29 de abril y presenciaron la ceremonia de "picar puntos", que consistía en señalar con un puntero la parte del libro sobre la que debía versar el examen. Con este objeto se colocaba el libro cerrado sobre un atril. El alumno introducía el puntero entre las hojas del libro, éste era abierto en la parte señalada y se descubría la materia del examen.

El único concurrente fue el doctor Lafargue, y los profesores designados para el concurso enviaron un oficio al Gobierno en que señalaron "que el solo candidato, doctor Lafargue, ha manifestado todos los conocimientos prácticos y teóricos en estos dos importantes ramos de la ciencia médica y que lo consideran altamente apto para enseñarlos. Su disertación sobre "los usos del bazo", ha quedado entre nosotros como muestra de la extensión y profundidad de sus estudios en la anatomía y fisiología comparada".

El decreto de nombramiento fue dictado el 7 de mayo de $1841^{2}$. 


\section{¿Quién era el doctor Lafargue?}

El joven Lafargue, nacido en Montpellier, se distinguió a temprana edad por una aptitud especial y vocación decidida para el estudio de las ciencias. Sus padres lo pusieron en el colegio de Agen, donde hizo con brillo sus estudios preparatorios, mostrando gran inclinación por las ciencias naturales. De ahí pasó a París para seguir los estudios de medicina. El año 1832, obtuvo por concurso un internado. El estallido de una epidemia de cólera, sirvió para que Lafargue prestara sus servicios en los hospitales de París, como alumno interno, con tal entereza y pasión, que merecieron una medalla de oro de la administración de los hospitales de París.

En 1835, último año de su internado, escribió una memoria sobre "Las funciones cerebrales de los animales", apoyándose en experimentos fisiológicos sobre animales vivos, estudio premiado por la Academia de Medicina de Burdeos, que propuso el tema.

La misma Academia instituyó un premio honorífico y pecuniario al que presentase la mejor memoria "Sobre determinar lo que hay de positivo entre la localización de las ideas y facultades intelectuales, tomando por guía la anatomía comparada, la fisiología y la patología". Lafargue obtuvo el premio, regresando a París para continuar con infatigable ardor los estudios médicos. Sin embargo, en 1840 volvió a Burdeos, a oponerse a un cargo de cirujano y no obstante el informe de la comisión que lo declaraba el mejor, aquel destino fue dado a otro.

Dice José Joaquín Aguirre, citado por Domingo Amunátegui", "que de aquí data la cadena de sufrimientos morales que han azotado la vida del doctor Lafargue. Tan profunda debió ser la impresión que recibió, que abandonando toda idea de celebridad, se expatrió de Francia, dirigiéndose a Chile, como si hubiese querido poner el globo de por medio entre su patria y su asilo".

En 1843, hizo un viaje al sur de Chile, para estudiar las enfermedades reinantes, efectuando excursiones a la cordillera y descubriendo las condiciones geológicas de los terrenos adyacentes al volcán Antuco. Sobre esta materia escribió una memoria que envió a Francia mereciendo como digna recompensa la cruz de la Legión de Honor.

Por ese tiempo, algunos escritos de prensa agriaron de nuevo su espíritu, decidiendo hacer un viaje a Bolivia en 1845, desde donde pasó a instalarse en el Perú. Los diarios de Lima le prodigaron los más altos y merecidos elogios.

Regresó a Valparaíso en 1849 y sus amigos notaron por la excentricidad de su vida y las preocupaciones sombrías de su espíritu, las afecciones morales que perturbaban su reposo. Antecedentes encontrados en sus papeles, lo muestran afectado de una negra misantropía, odiando a la sociedad, quejándose de la injusticia de los hombres. Se dice que una quiebra, arrebatándole sus economías, precipitó la catástrofe a que estas preocupaciones lo conducían y el 10 de agosto de 1850, hallaron su cadáver exangüe, ultimado por una herida hecha en la arteria crural.

Sus discípulos, como lo escribió José Joaquín Aguirre (cit. por 2) "no han olvidado el celo que mostró el doctor Lafargue por la instrucción de la juventud, ni la claridad de su exposición, ni la riqueza de su enseñanza. Los alumnos de cursos superiores venían a sus clases, así como personas extrañas a los estudios y médicos ya formados que no desdeñaban asistir a las lecciones de Lafargue en el Hospital San Juan de Dios"-4.

Similares conceptos se encuentran en las obras de Salas Olano y José Grossi ${ }^{5,6}$.

\section{El episodio de la "mano femenina". El doctor Carlos Buston}

Es interesante conocer un episodio de la vida de Lafargue, el que también involucró al médico francés Carlos Buston, cirujano de los ejércitos de Napoleón, llegado a Chile en julio de 1823, quien junto con el doctor Guillermo Blest, el 21 de mayo de 1831, participó en la autopsia del fallecido Vice-Presidente de la República Jose Tomas Ovalle ${ }^{3}$. Dicho episodio relatado primero por Pedro Lautaro Ferrer y más tarde por Miguel Luis Amunátegui, bajo el título de "Anécdotas Literarias", se publicó en el primer número de la "Revista de Valparaíso", dirigida por la poetisa chilena Rosario Orrego de Uribe ${ }^{2,4}$.

Dice así: "En septiembre de 1843, el conductor de uno de los carretones de la policía de aseo de Santiago, encontró en un montón de basuras de la calle del Estado una mano horriblemente mutilada, sin piel y sin carne.

"Sin pérdida de tiempo, el carretero entregó aquel trozo humano, deforme y raspado a navaja, al Intendente de la Provincia, quien lo remitió al cirujano Carlos Buston, para que informara del asunto.

"El señor Buston expuso que el trozo remitido era una mano de mujer, que debió haber sido amputada cuatro días antes.

"Envióse entonces aquel sangriento miembro al profesor de anatomía Francisco Lafargue, quien ratificó por escrito en todas sus partes el informe de Buston.

"Con ocasión de este suceso, empezaron a contarse las cosas más extrañas.

"Algunos suponían que un marido celoso había asesinado a su mujer adúltera, descuartizándola presa por presa para ocultar su crimen.

"Otros sospechaban que algún amante frenético había dado muerte a alguna niña que se le resistía.

"Otros pensaban que los vendedores de empanadas tenían la costumbre de desenterrar los cadáveres para hacer con carne picadillo (pino) de empanadas, y que alguno de aquellos delincuentes había botado aquel manojo de huesos después de haber confeccionado el sangriento e inmundo guiso. 
"Los doctores Buston y Lafargue opinaban que la mano había servido de objeto de estudio para algún alumno de cirugía, fundándose en que aparecía descarnada científicamente.

"Los que eran poetas habían soltado las riendas a su imaginación. “¡Cuantas conjeturas!

"Aquella mano había estado cubierta con un guante, que la hacía más codiciada y seductora.

"Aquella mano había llevado en sus pulidos dedos anillos de brillantes.

"Aquella mano había cargado un pañuelo guarnecido de encajes, había jugueteado con una flor, había manejado un abanico.

"Aquella mano había recibido y escrito cartas de amor.

"Aquella mano había sido estrechada con ardor y besada con embriaguez.

"Aquella mano había hecho caricias...

"El conocimiento completo del informe facultativo modificó, sin embargo, algún tanto las primeras ilusiones a que el cuerpo del delito había dado origen.

"Los doctores Lafargue y Buston aseguraban que aquella mano no era la derecha, sino la izquierda.

“¡La mano izquierda!

"Esta circunstancia disminuía tanto la movilidad de aquel misterio de hueso que se tenia a la vista: pero siempre conservaba la personalidad de la heroína del drama cuyas peripecias se ignoraban.

“¡La mano había pertenecido a una mujer!

"Mientras los simples ciudadanos inventaban novelas más o menos ingeniosas, el Intendente de Santiago, el juez del crimen, los sabuesos de la policía y de la justicia rastreaban las huellas del delito.

"Después de muchas vueltas y revueltas, de muchas preguntas y declaraciones, se descubrió por fin la incógnita del problema.

"Un señor Bustamante, dueño de una hacienda situada no lejos de Santiago, había cazado y muerto en su fundo una leona, que había dado a sus sirvientes.

"Un negro había obtenido la mano izquierda de la fiera, le había sacado la piel con las garras sin descompaginarla, le había quitado la carne para comérsela, y por último, había arrojado el resto a la basura.

"El tal negro había puesto en conmoción a la capital de la Republica de Chile, dando bastante trabajo a las autoridades, y causado una mortificación amarga a profesores distinguidos.

"Este chasco ha redundado en provecho de la oscura ciencia médica, escribía entonces don Domingo Faustino Sarmiento. Un examen quirúrgico ha manifestado que la mujer tiene mano de león. ¿Tendrá también el corazón de tal?
Laval Manrique se pregunta: ¿pudo el doctor Lafargue confundir una mano de leona con una mano humana? Imposible, se contesta. Hemos buscado, agrega, con el mayor interés el proceso y no lo hemos encontrado. El señor director del Archivo Nacional que nos ha ayudado en esta pesquisa tampoco ha logrado dar con él. Hasta aquí las consideraciones de Laval Manrique? .

En "Recuerdos de la Escuela", Augusto Orrego Luco dice que Lafargue "era un viejecito triste, de una fisonomía delicada y melancólica, tenia una expresión doliente y un pliegue de amargura contraía sus labios. Era muy instruido y de una notable cultura literaria. Desde entonces (mayo de 1841), se instaló en esa sala (el anfiteatro). Ahí pasaba siempre solo, leyendo sus libros, haciendo sus trabajos, en medio de sus preparaciones anatómicas. Se recordaba como una leyenda de la Escuela, la vida de ese viejecito delgado, pálido, de ojos claros, de cabeza fina y largos cabellos canos, que andaba despacio y miraba lentamente con una sonrisa amable y bondadosa ${ }^{8}$.

\section{Resumen}

Se relata en esta comunicación la personalidad y datos biográficos del doctor Francisco Julio Lafargue, segundo profesor de anatomía y fisiología de la Escuela de Medicina de la Universidad de Chile, así como del doctor Carlos Buston, cirujano militar, transcribiéndose el episodio, considerado como "anécdota literaria", que involucró a ambos médicos en 1843.

\section{Referencias bibliográficas}

1.- Laval R E. El doctor Pedro Morán, la Escuela Médica de 1833 y la batalla de Rancagua. Rev Chilena Infectol 2011; 28: 484-7.

2.- Amunátegui S D. El Instituto Nacional bajo los rectorados de don Manuel Montt, don Francisco Puente y don Antonio Varas. (1835-1845). Santiago de Chile. Impta. Cervantes. 1891.

3.- Laval M E. Noticias sobre los médicos en Chile Siglo XVI, XVII, XVIII, XIX (A-B). Santiago de Chile. Ed. Historia Médica. 1970. Siglo XIX, letra L. (inédito).

4.- Ferrer P L. Historia General de la Medicina en Chile. Talca, Chile. Impta. Talca. 1904.

5.- Salas Olano E. Historia de la Medicina en Chile. Santiago de Chile. Impta. Vicuña Mackenna. 1894.

6.- Grossi J. Reseña del Progreso Médico en Chile. Valparaíso, Chile. Impta. de la Opinión. 1895.

7.- Laval M E. Evolución de la enseñanza de la anatomía en Chile. An Chil Hist Med 1964; 6 (2): 47-8.

8.- Orrego L A. Recuerdos de la Escuela. Santiago de Chile. Impta. Universitaria, 1922. 